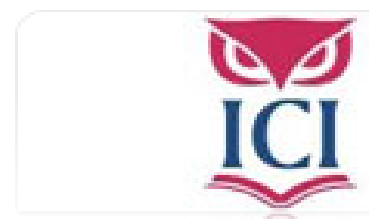

IUS. Revista del Instituto de Ciencias Jurídicas de Puebla A.C.

ISSN: 1870-2147

revista.ius@hotmail.com

Instituto de Ciencias Jurídicas de Puebla A. C.

México

Pérez Hernández, Lissette

El derecho entre la educación cívica y la etica, cuestión de presente

IUS. Revista del Instituto de Ciencias Jurídicas de Puebla A.C., núm. 21, 2008, pp. 206-221

Instituto de Ciencias Jurídicas de Puebla A. C.

Puebla, México 


\section{EL DERECHO ENTRE LA EDUCACIÓN CÍVICA Y LA ETICA, CUESTIÓN DE PRESENTE}

Lissette Pérez Hernández ${ }^{*}$

SUMARIO

Introducción

1. El principio de legalidad como contenido necesario

de la educación cívica (algunas razones)

2. La Constitución, principal reservorio jurídico de los valores que consagra una sociedad

3. La educación cívica y la democracia

4. Otra vez sobre la educación cívica (a modo de conclusiones)

\section{RESUMEN}

El presente artículo aborda algunas aristas de la interrelación existente entre la ética, el derecho y la educación cívica. Persigue como objetivo general propiciar el debate en torno a las mismas. Con tal propósito se seleccionaron para su análisis las siguientes ideas claves: que a partir del carácter activo y transformador que tiene el derecho, el principio de legalidad puede considerarse como un fundamento ético propulsor de la conciencia social, en particular la jurídica, de fuerte incidencia en el progreso educativo y cultural de la sociedad; que el conocimiento y enseñanza efectiva de los contenidos regulados por la Constitución de un país, como principal reservorio jurídico de los valores que consagra una sociedad, pudieran ser considerados respectivamente, derecho y deber cívico, y por último, que la participación ciudadana en el ejercicio del poder político, depende en gran medida de

\section{ABSTRACT}

The present article approaches some edges of the existent interrelation among the Ethics, the Right and the Civic Education. It pursues as general objective to propitiate the debate around the same ones. With such a purpose they were selected for their analysis the following ideas keys: that starting from the active character and transformer that he/she is entitled, the principle of legality it can be considered as a foundation ethical propeller of the social conscience, in particular the artificial one, of strong incidence in the educational and cultural progress of the society; that the knowledge and effective teaching of the contents regulated by the Constitution of a country, as main juridical reservorio of the values that consecrates a society, could be considered respectively, right and civic duty, and lastly that the civic participation in the exercise of the political power, depends

* Doctora en derecho y profesora titular de derecho constitucional de la Universidad de La Habana. 
los niveles de cultura jurídica alcanzados por los sujetos políticamente activos de la sociedad. Luego de analizar los puntos anteriores se concluye que la educación cívica constituye un área de actividad que compromete conjuntamente al Estado y a la sociedad civil y que el contenido axiológico del derecho nutre el fundamento ético de la misma y es esencial para el cumplimiento del principio de legalidad in great measure of the levels of artificial culture reached by the politically active fellows of the society. After analyzing the previous points you concludes that the civic education constitutes an activity area that commits jointly to the State and the civil society and that the contained axiologic of the Right nurtures the ethical foundation of the same one and it is essential for the execution of the principle of legality.

... los hombres, sea consciente o inconscientemente, derivan sus ideas morales, en última instancia, de las condiciones prácticas en que se basa su situación de clase: de las relaciones económicas. ${ }^{1}$

... la verdad es que cada clase y hasta cada profesión tienen su moral propia. $^{2}$

el Derecho es un modelo conductual paradigmático, que ofrece o debe ofrecer un conjunto de dictados de conducta que sean efectivamente modélicos del mundo éticamente superior por el que luchamos. En ese sentido brindo al Derecho un papel y una función deontológica $y$ de altísimo contenido axiológico que puede ser la alternativa ética al mundo individualista y egoísta del capitalismo y particularmente del neoliberalismo. ${ }^{3}$

La importancia trascendental que puede tener en cualquier sociedad la formación cívica, se pone de manifiesto al analizar de forma integral las diferentes dimensiones que alcanzan sus contenidos y la estrecha relación que tienen éstos, con los que considero, sus pilares básicos: la historia, los valores, y la legalidad.

En su esencia, la asumimos como la formación del individuo en sociedad, para el cumplimiento de los deberes y el conocimiento y defensa de los derechos, la comprensión de los principios que rigen la sociedad, su organización sociopolítica y funcionamiento, así como la vía educativa

${ }^{1}$ F. Engels, Anti-Düring, Ed. Pueblos Unidos, Montevideo, 1960, p. 115.

${ }^{2}$ F. Engels, Ludwig Feuerbach y el fin de la filosofía clásica alemana, en Obras escogidas en dos tomos, t. 2, Ed. Progreso, Moscú, 1971, p. 406.

3 Julio Fernández Bulté, Teoria del Estado y del derecho, t. 11, Editorial Félix Varela, La Habana, 2002. 
idónea para desarrollar en los ciudadanos el sentido de responsabilidad ante un actuar en perjuicio de un individuo y/o la sociedad. Es frecuente que se dirija principalmente a niños y jóvenes, para que la escuela contribuya de conjunto con la familia a desarrollar en ellos la condición activa del ser social, desde las primeras edades, aunque continúe siendo importante en todas las edades y niveles de enseñanza, admitiéndola como una cuestión insoslayable de presente. ${ }^{4}$

Sobre esa base se sostiene como idea central en el presente trabajo, la interrelación existente entre la ética, el derecho y la educación cívica y es su objetivo más general analizar brevemente las siguientes propuestas como posibles ejes, en futuros debates sobre el tema.

Primera: que a partir del carácter activo y transformador que tiene el derecho, el principio de legalidad puede considerarse como un fundamento ético propulsor de la conciencia social, en particular la jurídica, de fuerte incidencia en el progreso educativo y cultural de la sociedad.

Segunda: que el conocimiento y enseñanza efectiva de los contenidos regulados por la Constitución de un país, como principal reservorio jurídico de los valores que consagra una sociedad, pudieran ser considerados respectivamente, derecho y deber cívico.

Tercera: que la participación ciudadana en el ejercicio del poder político, depende en gran medida de los niveles de cultura jurídica alcanzados por los sujetos políticamente activos de la sociedad.

\section{El PRINCIPIO de LEgalidAd COMO CONTENIDO NECESARIO de LA EDUCACIÓN cívica (algunas RAZONES)}

El desconocimiento de la ley no exime de su cumplimiento ${ }^{5}$

Defender la legalidad como principio supone, primero que todo, comprenderla en su sentido amplio; como línea de acción, método de dirección, programa, aspiración y fin; segundo, fundamentar su nexo con las normas derivado de la sujeción que tiene como principio al derecho, como un todo que las incluye, sin hacerlas depender absolutamente del cumplimiento más o menos estricto de las mismas; y en tercer lugar, defender que la legalidad expresa intereses, voluntad, cultura, tradiciones y la realización efectiva de los valores que consagra una sociedad, en un momento dado.

La legalidad así entendida se puede manifestar como patrón, control, prevención, proyección, límite y fuente de educación; en tanto interviene

\footnotetext{
${ }^{4}$ Cano Ll. María Teresa, Compendio de cívica, Cultural, La Habana, 1944, p. 10 ("cívica del presente, no la del futuro ciudadano").

${ }^{5}$ Principio general del derecho.
} 
en la legalización de los marcos de actuación del mecanismo estatal y los ciudadanos, debe amparar la realización jurídica desde el origen mismo de las normas. Bajo sus presupuestos se establecen políticas y conforme a sus reglas se pueden verificar la eficacia y vigencia de las normas jurídicas.

Por su esencial adhesión a las relaciones de poder, y fuerte incidencia en la vida social, la legalidad es una fórmula de carácter político, que consideramos vital como fuente de legitimación y consenso, en tanto, cumplir sus mandatos es equivalente a respetar el derecho, es decir, actuar conforme a derecho y a velar y dirigir acciones que garanticen su cumplimiento. Debe ser fuente de seguridad y garantía originaria del orden político social constituido. Su práctica y exigencia consecuente refleja civilidad y actuar democrático, por lo que puede tornarse por sí misma, en una semilla educativa ejemplar.

De forma responsable, tener en cuenta a la legalidad como principio de la vida política, exigencia de la sociedad civilizada y, como método admisible de dirección estatal, en planes y programas de formación cívica, convoca educativamente a la sociedad a la salvaguarda del orden, al respeto del derecho ajeno, a la certeza jurídica y a la confianza en los órganos e instituciones que generan las normas y/o inciden en su cumplimiento.

Coincidimos con el profesor Fernández Bulté: "el dominio del derecho y su correcta aplicación exigen el conocimiento científico, aunque algunos se empeñen en olvidarlo, el derecho no admite improvisaciones, adulteraciones, voluntarismos o desviaciones de las leyes cardinales que lo rigen y de sus principios fundamentales. Normalmente cuando se burlan esas leyes, esas regularidades y esos principios, el contenido jurídico del derecho termina jugando una mala pasada a los que creyeron que podían olvidarlas".

Sucede que aún cuando las normas jurídicas se dictan para ser cumplidas, la eficacia de sus postulados bajo determinadas circunstancias puede variar. Las causas pueden ser diversas. Realizando el análisis desde una perspectiva axiológica, los motivos pueden derivar en buena medida de la capacidad que tengan las normas jurídicas de reflejar los patrones de conducta moralmente aceptados por la sociedad; de cómo se revelan en las normas y en su ejercicio, los fundamentos del derecho, en particular los principios éticos fundacionales de justicia, equidad y razón, pues, toda sociedad, motivada por tradiciones, intereses, historia y cultura debe privilegiar sus "propios" valores, juridificándolos, exigiendo responsabilidad por su incumplimiento.

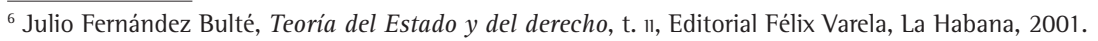


Lo ideal es que exista correspondencia entre éstos y aquéllas. Incluso más, el derecho, en virtud de su capacidad ética y las exigencias del desarrollo y el progreso, puede promover nuevas conductas, anticiparse a la moral predominante; de hecho, en ocasiones lo hace, con el objetivo entre otros, de transformar sectores, ramas, la concepción de determinadas tipologías, fundamentos filosóficos, científicos, políticos y con ello hasta a la misma sociedad, pero la historia demuestra que la eficacia de esas normas ha sido posible sólo allí, donde los "adelantos" han recibido la adhesión y el consentimiento de las masas y ha existido como consecuencia una transformación paralela de los valores que encierran esas normas.

En tanto alcanzar con las normas el efecto social pretendido por el legislador, estará condicionado por las circunstancias reales, materiales y espirituales de vida de la sociedad a la que van dirigidas, la eficacia del derecho se puede considerar su meta estratégica en cuanto regulador: ¿hasta qué punto se logran la organización y orden de la vida social, el cumplimiento por todos de las obligaciones jurídicas, las oportunidades de ejercicio de los derechos subjetivos; hasta qué punto la arbitrariedad y la falta de control se excluyen de la vida de la sociedad? En otras palabras, la eficacia del derecho tiene por indicador general lo que podemos denominar "valor realizado" y, por tanto, el estado de la legalidad, el nivel del orden jurídico en conjunto y en todos sus eslabones. ${ }^{7}$

Considera el profesor López Bombino que los valores son resortes sociales, ponderados, defendidos, apreciados, deseados, buscados y considerados importantes por toda la sociedad, por una parte de ésta o por grupos de individuos que de hecho operan como reguladores del comportamiento del sujeto. Los valores mueven el comportamiento y guían la actividad humana en todas sus manifestaciones. ${ }^{8}$ Desde una perspectiva jurídica, pudieran considerarse valores aquellos preceptos que fundamentan la organización estatal, el ordenamiento jurídico y a una sociedad dada, por el contenido cultural, histórico y moral que entrañan, a partir de las características propias del sistema sociopolítico que los desarrolla.

Lo anterior apunta hacia la posible perspectiva de reconocer por su significación y alcance social el principio de legalidad como un valor de

${ }^{7}$ Ver Serguéi Alexéev, El socialismo y el derecho. El derecho en la vida de la sociedad, Editorial Progreso, Moscú, 1989, p. 154.

${ }^{8}$ Luis R. López Bombino, (Coord.). Ética y sociedad, t. 11, Editorial Félix Varela, La Habana, 2002, pp. $1-3$. 
carácter político, ${ }^{9}$ a partir del cual se puede erigir también como puntal ético del derecho. De lo que resulta que el derecho en su conjunto y la legalidad como principio, sobre la base de los fundamentos éticos de ambos, deban ser considerados fuente directa de educación cívica.

El derecho es arsenal axiológico, político e ideológico. Sus contenidos más generales debidamente seleccionados ${ }^{10} \mathrm{y}$ bien sistematizados en programas de estudios principalmente dirigidos a niños y jóvenes, pueden considerarse un factor de desarrollo social, un multiplicador directo de los intereses que salvaguarda la sociedad, un reproductor de los espacios para difundir la ética de los patrones de conducta que regula, puede articular consensos, fortalecer la hegemonía política, rescatar la cultura histórica de una nación y fortalecer la identidad nacional y la ideología predominante.

Para el logro de lo anterior, considero además, tal y como apuntó el profesor Álvarez Tabío, que "es necesario destacar las garantías ideológicas, en particular la educación de los funcionarios y de todos los trabajadores en el espíritu de una profunda comprensión de la necesidad de acatar la legalidad. Graves perjuicios se derivan de la errónea tesis de contraponer la legalidad al llamado 'enfoque político' de los problemas. Lo cierto es que el correcto enfoque político de un problema regulado legalmente es, precisamente, la aplicación estricta de las leyes vigentes en la materia de que se trate". ${ }^{11}$

En resumen, el actuar ético y moral presupone la existencia de principios que a nivel colectivo cristalizan en el derecho. Existen sin dudas, conexiones de ciertos núcleos éticos con disposiciones políticas y jurídicas. Las normas deben ganar su propia legitimidad en el campo ético, de la

\footnotetext{
${ }_{9}$ José Ramón Fabelo Corzo y González Palmira, Edith, "Para un estudio de la democracia como valor político de la sociedad cubana actual”, en Luis R. López Bombino (Compilador principal), Por una nueva ética, Editorial Félix Varela, La Habana, 2004, p. 105. Seguimos el criterio metodológico defendido por los autores para concebir un valor político analizando la democracia y por asociación concluimos que también pudiera la legalidad considerarse como tal. Puede fundamentarse además a partir del concepto de valor político que ofrece la profesora González Palmira en Luis R. López Bombino (Coord.), Ética $y$ sociedad, t. 11, Editorial Félix Varela, La Habana, 2002, p. 161: "Un valor político en su dimensión objetiva es todo elemento de la actividad política (institución, relación, norma, fórmula, mecanismo, sujeto, conducta, aspecto de la conciencia política) que tenga una significación social positiva, ya sea porque existe realmente en la sociedad o que aún sin existir, pueda y deba hacerlo en condiciones históricas dadas."

${ }^{10}$ Los contenidos mínimos que asumimos como básicos, son los siguientes: la Constitución, las leyes, los derechos, la organización estatal, la participación ciudadana, la responsabilidad y la toma de decisiones.

${ }^{11}$ Fernando Álvarez Tabío, Comentarios a la Constitución socialista, Editorial de Ciencias Sociales, La Habana, 1985, p. 237.
} 
misma manera que no basta la convicción ética de ciertos principios para que tengan fuerza material en las sociedades. ${ }^{12}$

\section{La Constitución, principal Reservorio juRídico de los valores oUe CONSAGRA UNA SOCIEDAD}

Que las masas... dominen el contenido de la Constitución y de las leyes. Que conozcan perfectamente cuáles son sus derechos y cuáles son las vías de ejercerlo. Que conozcan cuáles son las normas que rigen nuestras actividades, para que las cumplan y para que sean celosas vigilantes de su cumplimiento. ${ }^{13}$

Los hombres han olvidado esa verdad, pero tú no debes olvidarla. Eres responsable para siempre de lo que has domesticado. ${ }^{14}$

A diferencia de otras épocas de la historia, falta en el presente la aceptación pacífica de normas de conducta éticas de general acatamiento; vivimos con la suma de varias morales integradas ${ }^{15}$ que de forma más $o$ menos exitosa se incluyen para nutrir los ordenamientos jurídicos, contribuyendo a la realización de los valores predominantes en una sociedad. Su conocimiento y transmisión de generación a generación ya no pueden ser un proceso simple y espontáneo.

El cumplimiento consciente de las normas jurídicas exige, cada vez más, un mayor nivel de educación jurídica esencial, de conocimiento de la estructura, las funciones, las instituciones y las normas jurídicas fundamentales. El nivel de educación jurídica se convierte en un pilar cognoscitivo de la estimativa de valores sociales y constituye un fundamento esencial de la ética. ${ }^{16}$

Dentro del ordenamiento jurídico nacional, la Constitución es el principal reservorio jurídico de los valores que consagra una sociedad. En su selección y salvaguarda influyen los intereses políticos, pero también la historia, las tradiciones y la fuerza ordenadora de la sabiduría y la re-

${ }^{12}$ Ver "Lineamientos curriculares para el área de ética y valores humanos. Orientaciones para la formulación de los currículos en Constitución política y democracia”, Raíces y Ramas de la Discusión Ética, http://www.campus-oei.org/valores/boletin6b.htm\# 1

${ }^{13}$ Raúl Castro Ruz, "Discurso pronunciado en el Acto de Proclamación de la Constitución de 24 de febrero de 1976, Bohemia, 5 de marzo de 1976, p. 58.

${ }^{14}$ Antoine de Saint Exuperi, El principito, Editorial Gente Nueva, La Habana, 2006, p. 100.

${ }^{15}$ Ver Roberto Dromí, Derecho administrativo, Ciudad Argentina, Buenos Aires, 2000, pp. 26-27.

${ }^{16}$ Ver Francisco Varona Duque de Estrada, "Prólogo", D. P. Kotov, Problemas de la ética judicial, Ministerio de Justicia, La Habana, 1985, p. 24. 
flexión. Su cumplimiento debe ser la combinación de elementos materiales y formales, razonables y espirituales.

"La aceptación de la axiología jurídica en los marcos constitucionales ha permitido sostener que la Constitución no está compuesta solamente de reglas y principios, de mandatos y preceptos declarativos, sino que además incluye estándares de comportamiento no prescriptivos, disposiciones que tratan de fijar la idea de qué se manda o con qué intención se manda, lo que brinda una dimensión de moralidad y proyecta una solución a la relación poder/sociedad/derecho en una perspectiva histórica y iusfilosófica." ${ }^{17}$

Una Constitución debe ser fuente de legitimación material y formal del orden jurídico y político, y en tal sentido es parámetro de validez del resto de las normas. Ella determina los órganos y procesos de creación jurídica y contiene normas, principios que constituyen mandatos para su desarrollo posterior por los órganos de poder público, razones por las cuales constituye el fundamento que facilita y procura la base de la unidad interna del ordenamiento jurídico. En tal sentido es, además, norma suprema del sistema normativo y del régimen socioeconómico y político. ${ }^{18}$

Constituye la máxima expresión del marco institucional de una sociedad, sintesis de un proceso acumulativo, orientadora de cambios, en tanto es vía de adecuar la sociedad a nuevas circunstancias.

Conocer una Constitución puede significar conocer a un pueblo, adentrarse en su historia ${ }^{19}$ y constatar jurídicamente el alcance de sus conquistas más legítimas y de los valores compartidos por la sociedad. La Constitución como decisión del pueblo soberano, es además de un acto jurídico, un trascendente documento político, un acto del pueblo que construye su gobierno.

Dominar los contenidos constitucionales debiera considerarse derecho y deber: derecho, primero, si se tienen en cuenta la historia, las conquistas y valores que formaliza jurídicamente la Ley Suprema; segundo, porque

\footnotetext{
${ }^{17}$ Carlos Villabella Armengol, La axiología de los derechos humanos en Cuba, en lissette Pérez Hernández y Martha Prieto Valdés (Comps.), Temas de derecho constitucional cubano, Editorial Félix Varela, La Habana, 2000, p. 291.

${ }^{18}$ Ver Lissette Pérez y Martha Prieto, "Los derechos fundamentales. Algunas consideraciones doctrinales necesarias para su análisis”, en Lissette Pérez Hernández y Martha Prieto Valdés (Comps.), Temas de derecho constitucional, Editorial Félix Varela, La Habana, 2002.

${ }^{19}$ Armando Hart Dávalos, Cultura, ética y politica solidaria, "Es importante que los especialistas en derecho, y entre ellos los estudiantes y profesores, se empeñen en estudiar estos tres textos legales (1869; 1901 ; 1940), porque en ellos pueden encontrar la evolución del pensamiento jurídico cubano antes de la Revolución que sirvió de antecedente al proceso iniciado en el Moncada y La historia me absolverá y continuado con la declaración del carácter socialista de la Revolución en 1961. http://www.granma. cubaweb.cu/secciones/comentarios/nacional-07.htm.
} 
la Constitución reconoce y garantiza derechos individuales y colectivos, como resultado democrático y expresión de la soberanía popular; y por último, porque uno de los deberes fundamentales del ciudadano es cumplir la Constitución y las leyes, ${ }^{20}$ y conocerla por tanto, se convierte en condición necesaria para su cumplimiento.

También debiera considerarse deber, considero que en una doble dimensión: primero, deber ciudadano, como correlato del derecho que se esgrime a partir de los imperativos éticos contenidos en el texto constitucional y el nivel de conciencia jurídica alcanzado por la sociedad. De esta forma los contenidos constitucionales pueden constituir parte esencial de los parámetros que orienten el buen comportamiento; segundo, deber institucional, en tanto el conocimiento debe ser debidamente orientado y convenientemente exigido. ${ }^{21}$ El conocimiento espontáneo de los contenidos constitucionales no garantiza, ni material ni formalmente su cumplimiento ni su necesaria defensa.

\section{La educación CÍVICA Y La deMOCRACIA}

El hombre, cuya grandeza, es decir, cuya dignidad estriba en que puede ser el sustrato y el agente de realización de los valores... ${ }^{22}$

En pueblos compuestos de elementos cultos e incultos, los incultos gobernarán, por su hábito de agredir y resolver las dudas con su mano: alli donde los cultos no aprendan el arte del gobierno. La masa inculta es perezosa, y timida en las cosas de la inteligencia, y quiere que la gobiernen bien; pero si el gobierno le lastima, se lo sacude y gobierna ella. ${ }^{23}$

Que se alcancen los niveles medios de formación cívica de los ciudadanos es responsabilidad de la familia y del Estado, y al servicio de la misma pueden estar todos los medios de difusión conocidos y otros por crear, pero su solidez será mayor si desde la primera infancia se educa con tales objetivos. La escuela es el centro capaz de multiplicar a través de maestros y profesores tal formación, incorporando al logro de esos objetivos

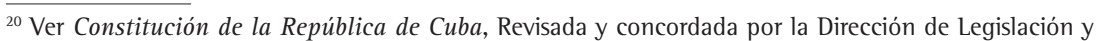
Asesoria del Ministerio de Justicia, La Habana, 2005, art. 66.

${ }^{21}$ En algunas constituciones se reconoce formalmente la obligatoriedad del estudio de la Constitución y la instrucción cívica. Ver Constitución Politica de Colombia, Art. 41.

${ }^{22}$ Luis Recasens Sichés, Vida humana, sociedad y derecho. Fundamentación de la filosofía del derecho, Editorial Porrúa, México, 1952, p. 539.

${ }^{23}$ José Martí, Nuestra América I, Centro de Estudios Martianos, 2001 (Multimedia), Vol. 6, p. 17. 
a todos los actores de la localidad y a la propia comunidad, de forma tal que los ciudadanos puedan reproducir la información recibida, ampliarla y controlarla a lo largo de todo su desarrollo.

En esa dirección, la educación cívica se puede constituir a su vez en un eficaz mecanismo de control social, pues a través de ella es posible promover una cultura de conocimiento de las normas morales y jurídicas que asegure potencialmente la participación de todos y la asimilación consciente de los valores aceptados socialmente.

En la actualidad presenciamos una crisis de representación política en el Estado. Para algunos autores consecuencia paradójica del progreso, ${ }^{24}$ que aleja cada vez más a los centros de decisión de los electores y con ello de los interesados, creciendo de forma intempestiva el número de actores políticos organizados y los canales intermedios de gestión y solución a las demandas populares, que crean como consecuencia de ello, oleadas de insatisfacción, descrédito y desinterés político. De ahí que uno de los retos más acuciantes de los pueblos modernos sea crear las vías que propicien la participación ${ }^{25}$ real en el ejercicio del poder y, con ellas, lograr la eficacia en la gestión para la solución de los problemas comunales, para que se acerquen a la base de la toma de decisiones sobre aquellos temas que afectan directamente a la comunidad y se conviertan los vecinos en sujetos, como mínimo, del control directo de la gestión y de la confianza depositada, y a su vez, como consecuencia, del poder.

Es decir, los niveles de gobernabilidad y efectividad de la gestión de gobierno, en particular la local, están condicionados por la democracia y la participación real y consciente que ésta traiga consigo. La democracia requiere de la participación de los ciudadanos, los electores, en los asuntos propios de la comunidad, para lo cual es imprescindible desarrollar vías que pongan a su alcance las habilidades necesarias para hacerlo posible; tales habilidades pueden obtenerse como fruto de una sistemática y progresiva formación cívica. Exige la acción consciente del Estado en la educación del ciudadano sobre su función en el autogobierno, lo que supone enseñar a gobernar sobre la base de la formación de una conciencia política activa

\footnotetext{
${ }^{24}$ Ver Jordi Borja, Descentralización y participación ciudadana, Instituto de Estudios de Administración Local, Madrid, 1987, p. 19.

25 "La participación debe concebirse como un proceso educativo, consciente, que establece fines y compromisos de los sujetos implicados, que promueve aprendizajes de vínculos y actitudes y donde la calidad de la misma está dada en la toma de decisiones". Relatoría Taller Nacional "Desarrollo Local: Retos y Perspectivas en Cuba", Santiago de Cuba, 14 al 16 de mayo 2004, p. 15.
} 
que le permita a éste conocer cómo, dónde, por qué y para qué participar, ${ }^{26}$ para lo que es necesario ver a la gente más que como objeto de política, como sujeto de ella, como participantes directos en la toma de decisiones. Una enseñanza donde las categorías soberanía, legitimidad y democracia sean de acceso inmediato y objeto de ejercicio y realización cotidiana.

La democracia no es sólo una forma o método de gobierno; es, como dice Arblaster, un modo de vida ${ }^{27}$ y por ello es preciso crear culturas de participación ciudadana. No basta con transformar la norma, aunque el derecho como conjunto de normas que recoge los juicios de valor esenciales de la sociedad puede y debe contribuir a la transformación de la sociedad. Es la pedagogía cotidiana de la democracia, invadiendo todos los espacios de la vida social, la que realmente puede transformar la sociedad. De esta forma la educación es también para este propósito un pilar indiscutible, pero no la educación únicamente como responsabilidad estatal, sino también la educación que deben recibir los estados de los pueblos ${ }^{28} \mathrm{a}$ través del ejercicio sistemático del control social, ${ }^{29}$ que contribuya al logro de una participación real y efectiva de la población en el diseño, ejecución, control y evaluación de las políticas.

La democracia existe por los ciudadanos y para los ciudadanos, de ahí que ambas instituciones, democracia y ciudadanía se condicionen mutuamente. El ejercicio cotidiano de la ciudadanía conduce a la realización de la democracia. No hay auténtica democracia sin ciudadanos plenos. Ser ciudadano ${ }^{30}$ es muchas veces una condición indispensable para poder "realizar" democracia; "hacer" como ciudadano es dar existencia a la democracia, convirtiéndola en una práctica viva de la sociedad. En otras palabras, la construcción de la democracia debe ser producto del ejercicio de la ciudadanía y su responsabilidad. La democracia es una obra promovida

${ }^{26}$ Giovanni Lobrano, Modelo romano y constitucionalismo moderno, Universidad de Extremado de Colombia, 1990, p. 49.

${ }^{27}$ Anthony Arblaster, Democracia, Alianza Editorial, Madrid, 1992, p. 95.

${ }^{28}$ Ver C. Marx, Crítica del programa de Gotha, en Obras escogidas, t. 11, Editorial Progreso, Moscú, 1971 , p. 27.

${ }^{29}$ Pérez Hernández, Lissette, "Algunas consideraciones en torno a la democracia” en Lissette Pérez Hernández y Martha Prieto Valdés (Comps.), Temas de derecho constitucional, Editorial Félix Varela, La Habana, 2002.

${ }^{30}$ Ver José Martí, Traducciones II. Antigüedades griegas / Antigüedades romanas / Nociones de lógica, en Obras completas, Vol. 25. p. 108: "Este hábito de obediencia, esta reverencia a la autoridad, fue tal vez entre todas las cualidades de los romanos la que contribuyó más a hacer tan poderoso su influjo en la historia del mundo... Pero los romanos añadían a estos méritos su prontitud en obedecer las leyes, en someterse a la disciplina, en trabajar con sus conciudadanos por el bien común... En verdad que no hubo nunca pueblo alguno donde, con más celo que en Roma, fuese el bien del Estado el objeto de cada ciudadano." 
por la acción ciudadana, para lo cual los ciudadanos deben estar debida y suficientemente preparados.

Al respecto, nos preguntamos: ¿cuáles son los factores que condicionan los niveles de participación política? En particular, ¿en qué medida puede influir la educación cívica de una sociedad en los niveles de participación que se alcanzan?

A través de la educación cívica el Estado y la sociedad civil pueden divulgar la cultura democrática y promover una participación informada y responsable de los ciudadanos en los asuntos públicos.

El asunto tiene por lo menos dos niveles de análisis: el anterior, particularmente dirigido a motivar y desarrollar la capacidad participativa de los ciudadanos a través de programas especialmente concebidos para ese fin; y otro nivel, dirigido hacia la capacitación de los distintos actores sociales, con el objetivo de fortalecer los valores políticos y morales fundamentales que caracterizan la sociedad, comprender y analizar las bases jurídicas del desempeño del gobierno nacional y los gobiernos locales en el país.

En esta última dirección, la universidad pública adquiere una gran responsabilidad, debe estar al servicio de la sociedad: prever y planear la formación de recursos humanos necesarios para la administración pública y cualquier otro sector. Las instituciones de la educación superior pueden y deben desarrollar los vínculos necesarios con su entorno y responder a las necesidades del sistema socioeconómico y político de la sociedad de manera que sirva a la sociedad de forma activa, a través de las acciones que le dan contenido: la docencia, la investigación y la extensión universitaria. Las investigaciones científicas, sobre todo las derivadas de la educación de posgrado, deben ser el producto de una estrecha vinculación gobierno-universidad-sociedad. Los programas académicos de educación posgraduada deben responder a las demandas de servicios educativos de la sociedad, el gobierno y sus propias instituciones.

En especial, profundizar en la importancia del trabajo educativo en la enseñanza del derecho, con el objetivo de formar profesionales con altos conocimientos técnicos, científicos y culturales y potenciar la importancia de la formación ética como factor estratégico en la educación del jurista: profundizar en las perspectivas del trabajo integral educativo desde sus dimensiones axiológicas, estratégicas y pedagógicas; relacionar la formación integral del jurista con el desarrollo de la universidad, la comunidad y el país y promover acciones extensionistas de la universidad hacia la comunidad en distintas acciones culturales, docentes e investigativas, 
en tanto el derecho opera en la sociedad como un gran legitimador del poder, que habla, convence, seduce y se impone a través de las palabras de la ley. ${ }^{31}$

Derecho, democracia y valores se entrelazan como hilos de una complicada madeja. La sociedad se organiza tomando como fundamento los valores sociales que han resultado instituidos, a través de su reconocimiento jurídico; a su vez, de forma democrática y con la fuerza de la cultura, las tradiciones y la historia, muchos de los valores se llegan a reconocer oficialmente, en tanto son defendidos y conquistados por la sociedad. De tal condicionante recíproca, en la práctica se dan algunas paradojas; una de las que debe analizarse es el hecho de que la democracia como valor político por excelencia, al igual que otros valores formalmente se diseña y exige a través de herramientas jurídicas, y sin embargo no siempre se percibe o se realiza efectivamente, bajo el estricto cumplimiento de esos patrones a pesar de constituir un valor social ansiado, histórica y políticamente reconocido.

Como es fácil comprender, la realización efectiva de la democracia no depende exclusivamente del derecho, pero éste tiene sobradas herramientas para contribuir dialécticamente al rescate del ideal democrático, en el plano formal a través del perfeccionamiento institucional continuo de sus mecanismos, en especial de los llamados a potenciar la participación consciente y organizada de los ciudadanos, reflejando lo más posible intereses e ideales de la sociedad que está llamada a regular y en el plano material también, previniendo conductas y educando en el ejercicio cotidiano de la legalidad. En ambos planos, por supuesto, teniendo en cuenta las peculiaridades propias de cada momento histórico y lugar.

El reto educativo consiste entonces, en estructurar y ejecutar conscientemente, programas de estudio cívico que permitan comprender las relaciones objetivas y subjetivas que matizan la comprensión de las instituciones, su fundamento valorativo, su instrumentación jurídica y su realización práctica (lamentablemente no siempre coincidentes), las contradicciones internas que se pueden generar y las causas históricas y consecuencias implícitas en esos fenómenos; no hay doctrina ${ }^{32}$ sin historia, o no debería haberla, porque los conceptos y las instituciones no nacen de un vacío puro e intemporal, sino en un lugar y fechas conocidos y a

${ }^{31}$ Alicia E. C. Ruiz, Idas y vueltas. Por una teoría crítica del derecho, Universidad de Buenos Aires, 2001. p. 5.

${ }^{32}$ La autora en lugar de doctrina, alude a dogmática. 
consecuencia de procesos históricos de los que arrastran una carga quizás invisible, pero condicionante. ${ }^{33}$

\section{Otra vez sobre la educación cívica (a modo de conclusiones)}

Tengo fe... en la utilidad de la virtud. ${ }^{34}$

- La educación cívica no es solamente instrucción, constituye un proceso de aprendizaje que procura la adquisición de hábitos que propicien una conducta en la que esté presente el acatamiento y respeto de las normas que conforman el ordenamiento jurídico de una sociedad.

- La educación cívica constituye un área de actividad que compromete conjuntamente al Estado y a la sociedad civil. Es responsabilidad de todos. La cultura cívica debe ser una práctica constante, un modus vivendi y modus operandi,,$^{35}$ una actitud asumida en la convivencia social.

- La educación cívica constituye un eficaz mecanismo de control social, pues a través de ella se puede promover una cultura de conocimiento de las normas morales y jurídicas e impulsar la participación política y la asimilación consciente de los valores aceptados socialmente.

- El ejercicio consciente y estructurado de las funciones promocional, la de distribuir valores en la sociedad y la educativa, propias del derecho, nutren su fundamento ético y son esenciales para el cumplimiento del principio de legalidad.

- El ideal de educación cívica nos revela una nueva dimensión del actuar ético en tres vertientes: el actuar teleológico, el deontológico y el metodológico. A partir de esta triada se expresa el sentido axiológico del comportamiento humano. ${ }^{36}$

\footnotetext{
${ }^{33}$ F. Tomas y Valiente, citado por Alicia E. C. Ruiz, Op. cit., p. 49.

${ }^{34}$ José Martí, Ismaelillo, Editorial Letras Cubanas, La Habana, 1995, p. 7.

${ }^{35}$ Natasha Despotovich, "Una gran oportunidad para la democracia”, http://www.funglode.org/clavesdelmundo/2004/05/120504.htm

${ }^{36}$ Ver "Lineamientos curriculares para el área de ética y valores humanos. Orientaciones para la formulación de los currículos en Constitución política y democracia”, en Raíces y Ramas de la Discusión Ética. http://www.campus-oei.org/valores/boletin6b.htm\# 1
} 


\section{REFERENCIAS}

Alexéev Serguéi, El socialismo y el derecho. El derecho en la vida de la sociedad, Editorial Progreso, Moscú, 1989.

Álvarez Tabío, Fernando, Comentarios a la Constitución socialista, Editorial de Ciencias Sociales, La Habana, 1985.

Arblaster, Anthony, Democracia, Alianza Editorial, Madrid, 1992.

Cano Ll. María Teresa, Compendio de cívica, Cultural, La Habana, 1944.

Castro Ruz, Raúl, "Discurso pronunciado en el Acto de Proclamación de la Constitución de 24 de febrero de 1976", Bohemia, 5 de marzo de 1976.

Colectivo de autores, ¿Cómo ser mejor estudiante?, CEPES / UH, La Habana, 2001.

Saint Exuperi, Antoine de, El principito, Editorial Gente Nueva, La Habana, 2006.

Despotovich, Natasha, "Una gran oportunidad para la democracia", http:// www.funglode.org/clavesdelmundo/2004/05/120504.htm

Dromí, Roberto, Derecho administrativo, Ciudad Argentina, Buenos Aires, 2000.

Engels, F. Anti-Düring. Ed. Pueblos Unidos, Montevideo, 1960.

, Ludwig Feurbach y el fin de la filosofía clásica alemana. en Obras escogidas en dos tomos, Tomo 2, Ed. Progreso, Moscú, 1971.

Fernández Bulté, Julio, Teoría del Estado y del derecho, Tomo II, Editorial Félix Varela, La Habana, 2002.

García Cotarelo, Ramón, La formación cívico-constitucional en las aulas, Tomo I, Cuadernos de la uned, Madrid, 1987.

, La formación cívico-constitucional en las aulas, Tomo II, Cuadernos de la unED, Madrid, 1987.

Hart Dávalos, Armando, "Cultura, ética y política solidaria”, http://www. granma.cubaweb.cu/secciones/comentarios/nacional-07.htm

Jawitsch, Teoría general del derecho, Editorial de Ciencias Sociales, La Habana, 1988.

Kotov, D. P., Problemas de la ética judicial, Znanie, Moscú, 1976.

"Lineamientos curriculares para el área de ética y valores humanos. Orientaciones para la formulación de los currículos en Constitución política y democracia”, Raíces y Ramas de la Discusión Ética, http://www.campus-oei.org/valores/boletin6b.htm\# 1

Lobrano, Giovanni, Modelo romano y constitucionalismo moderno, Universidad de Extremado de Colombia, Colombia, 1990.

Lomov, B. F., "Comunicación y regulación social de la conducta del individuo", en Selección de lecturas sobre Introducción a la psicología, Ibarra 
Mustelier, Lourdes y Vasallo Barrueta, Norma (Comps.), Servigraf, La Habana, 2000.

López Bombino, Luis R. (Comp. y Coord. académico), El saber ético de ayer a hoy, Tomo I, Empresa Poligráfica de Holguín, SRGRAF, 2004.

, López Bombino, Luis R. (Comp. y Coord. académico), El saber ético de ayer a hoy, Tomo II, Empresa Poligráfica de Holguín, SRGRAF, 2004.

, Estudios éticos, Parte III, Facultad de Filosofía e Historia, Universidad de La Habana, La Habana, 1990.

, (Comp. principal), Por una nueva ética, Editorial Félix Varela, La Habana, 2004.

, (Coord. general), Ética y sociedad, Tomo I, Editorial Félix Varela, La Habana, 2002.

, (Coordinador general), Ética y sociedad, Tomo II, Editorial Félix Varela, La Habana, 2002.

Martí, José, Ismaelillo, Editorial Letras Cubanas, La Habana, 1995.

, Nuestra América I, en Obras completas, Vol. 6, Centro de Estudios Martianos, 2001 (Multimedia).

, Traducciones II, Antigüedades griegas - Antigüedades romanas

- Nociones de lógica, en Obras completas, Vol. 25, Centro de Estudios Martianos, 2001 (Multimedia).

Martí Lois, Juan, Ética profesional del maestro, Vicerrectoría del Trabajo Docente Educativo, Universidad de La Habana, La Habana, 1990.

Marx, Karl, Crítica del programa de Gotha, en Obras escogidas, t. II, Editorial Progreso, Moscú, 1971.

Palau Vera, J., La educación del ciudadano, Editores Provenza, Barcelona, 1928.

Pérez Hernández, Lissette y Prieto Valdés, Martha (Comps.), Temas de derecho constitucional, Editorial Félix Varela, La Habana, 2000.

Recasens Sichés, Luis, Vida humana, sociedad y derecho. Fundamentación de la filosofía del derecho, Editorial Porrúa, México, 1952.

Relatoria Taller Nacional "Desarrollo Local: Retos y Perspectivas en Cuba", Santiago de Cuba, 14 al 16 de mayo 2004.

Ruiz, Alicia E. C., Idas y vueltas. Por una teoría crítica del derecho, Universidad de Buenos Aires, 2001

Varona Duque de Estrada, Francisco, "Prólogo", en Kotov, D. P., Problemas de la ética judicial, Ministerio de Justicia, La Habana, 1985.

Villabella Armengol, Carlos, "La axiología de los derechos humanos en Cuba”, en Pérez Hernández, Lissette y Prieto Valdés, Martha (Comps.), Temas de derecho constitucional cubano, Editorial Félix Varela, La Habana, 2000. 